\title{
'Dental nurses should be renamed as diplomacy experts'
}

\author{
Interview by Kate Quinlan
}

Emma Phelan, 38, is a community dental nurse (sedation) for Cardiff and Vale University Health Board. Emma is also a dental nurse examiner for the National Examining Board for Dental Nurses (NEBDN). Originally from the Rhondda Valleys, she lives in Cardiff with her husband, daughter (9), son (5) and cat (11).

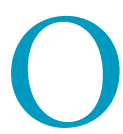
$\mathrm{n}$ a typical day I drive about

12 miles to work if I am in my base clinic in Pontypridd, which usually takes 40 minutes in rush hour traffic. If I am working further up the Rhondda, Cynon or Merthyr valley that can take over an hour to commute due to the narrow roads in the valley and volume of traffic. The University Dental Hospital is approximately two miles from my home so travelling there to work is far quicker.

I work 30 hours a week, Monday to Thursday. My start time is 8:45 am and finish time 4:45 pm with half an hour for lunch at 12:30 pm.

I have a varied job in the Community Dental Service. In the clinic where I am based there is a senior dental officer, senior orthodontist and orthodontic nurse, a community dental nurse, two dental officers who work alternate days, two DCT2s, and a receptionist, as well as me. We are a three-surgery set up and one of the surgeries is predominantly orthodontic. Our patients range from mainstream children who are unable to attend a general dental practice; additional care children; adults who are unable to be treated in the general dental service; and anxious children and teenagers. We also offer a domiciliary service, oral healthcare promotion and a paediatric general anaesthetic service.

Mondays I am clinical with the final year dental students who come to us on outreach visits. We have to select their patients carefully as the parent and patient have to agree to treatment being carried out by the student; also the patient has to be suitable for the student in terms of their behaviour and ability to be treated. I spend most of these days helping the students to patient-manage little humans and doing a lot of the talking as they are coming to us to learn these techniques.
Tuesdays I work with the DCT2s. In the morning we undertake the inhalation sedation (IHS) session. There are five patients booked on to this session: three treatments and two assessments. These patients take a lot out of the dental team as the level of support and encouragement needed is enormous to complete treatment plans. The age of the patients we treat ranges from eight years to 17 years. We do have some adult patients who find IHS works for them but they are by referral only from the Dental Hospital.

Tuesday afternoons are a normal clinical session with children ageing from very young up to 19 years, both mainstream and children who need additional care. We also treat adults who need additional care and who are unable to be treated in mainstream practice. Some of our

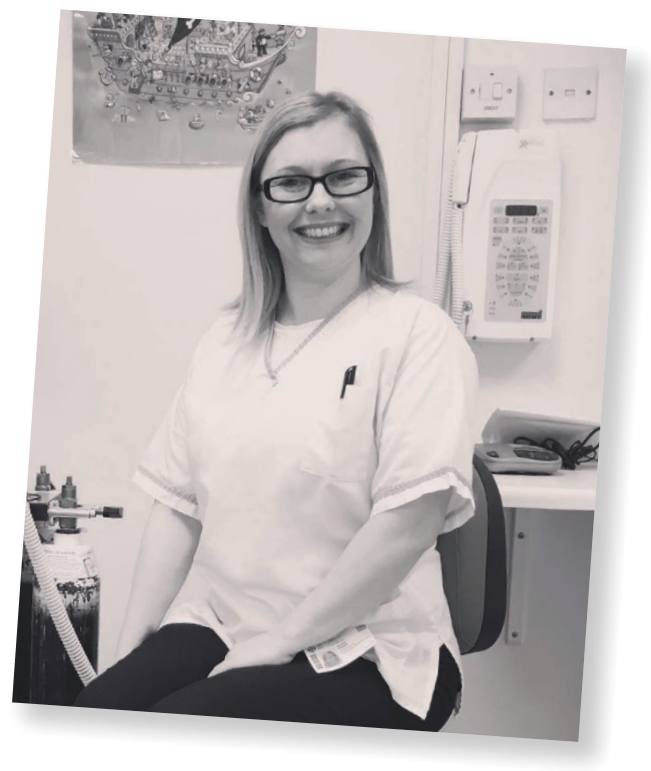

are referred by their dentist to be assessed and treatment planned for their extractions in the Royal Glamorgan Hospital. Patients fall into four categories: 1 . Multiple decayed teeth; 2. Acute pain and/or sepsis; 3 . Difficult management; and 4. Orthodontic extractions.

This clinic is rarely straightforward. The parent and patient do not always understand why they have been referred; the treatment plan may differ to what they were told by the GDP; the patient attends with the 'wrong person' to complete the paperwork, ie grandparent because the mum or dad is in work; the 'right person' attends but without legal documentation for example grandparent has legal custody but fails to bring the paperwork; or the patient is not suitable for XGA, for example orthodontic extractions for

\section{'These patients take a lot out of the dental team as the level of support and encouragement needed is enormous to complete treatment plans'}

patients can be extremely challenging in their behaviour and some can be the easiest patients you could ever meet. Patients in this category need continuity in care so we endeavour to keep one member of the dental team familiar to them. I have worked in this area for 16 years so have got to know my patients very well and am able to set the room and brief the dentist before they enter the surgery if required.

Wednesday mornings are the same as Tuesday morning with an IHS session, three treatments and two assessments, this time with the senior dental officer. On a Wednesday afternoon the general anaesthetic assessment clinic is run from Pontypridd. These patients premolars. This is the clinic where everything is then dealt with and problems are solved. Patients suitable for procedure are given their date and patients unsuitable for the procedure are placed on the correct pathway. Difficult conversations sometimes have to take place with the parents. We try to promote healthy diet and good oral healthcare at these sessions also, both with parent and child. We have excellent literature for them to read and understand which is produced by the Designed to Smile team who are also a division of our service. Unfortunately, in this part of the UK DMF rates are high so our patient numbers are also high on these sessions. 
4 Thursdays for me can either be clinical with the dental officer who works with us three days a week treating our regular patients, or in the University Dental Hospital Sedation Department, undertaking intravenous sedation on extremely nervous adults who are ASA I (American Society of Anesthesiologists) and ASA II or additional care adults who are ASA III. Again these patients can be extremely challenging. The most challenging are sometimes given oral sedation before they are given IV sedation and some may even need IV sedation with propofol and an anaesthetist. I feel these sessions are rewarding because you manage to achieve the treatment planned and the patient is able to cooperate, which under normal circumstances they wouldn't be able to.

In-between clinical duties I am also responsible for the daily upkeep of the clinic, the stock, ordering and maintenance of the equipment. I run the sedation waiting list for the Rhondda,
Cynon and Taff Ely CDS, I am Chair of the Clinical Advisory group and a member of the Quality and Safety group for CDS.

I love my relationships with my regular patients; you get to know little things about them and they really appreciate you asking about these things and taking the time to remember. I also love the special care element to the job as I feel I am really helping to make a difference in that person's oral care and in keeping them healthy. I also love mentoring other nurses and meeting new people when I examine for the Dental Nurse Diploma.

Working with the public can sometimes be very challenging as their perception of what they need can be a lot different to what they actually need. We work in a sector where a lot of people dislike or are phobic of going to the dentist, so initially they can be very aggressive or uncooperative. The challenge is to get that person to overcome this and learn to trust us, or to explain things to them and calm them. This can take a lot of emotion out of you as a person because we are only human after all and being told multiple times a week 'I hate the dentist' can be exasperating. Dental nurses should be renamed as diplomacy experts as we face the full force of the patients' frustration, anger or fear but by the time they reach the surgery their behaviour changes.

Outside work I enjoy running, reading, watching Formula 1 and American football. This year we're looking forward to a family holiday to Disneyland Paris.

I am vegetarian but the rest of the household are carnivores. Some people may think I am over the top with my children's diet and their sugar intake but I see on a daily basis what damage too frequent an intake can do to a child's mouth. A treat is fine but any more than that becomes junk.

\section{Charity focus}

\section{Supporting migrant workers in Singapore Henry Schein Dental UK supports HealthServe's dental clinic in Singapore by providing oral health treatment to migrant workers including prophylaxis, fillings, extractions, and surgical procedures. \\ HealthServe is a non-profit organisation dedicated to providing healing and hope to disadvantaged migrant workers in Singapore through a holistic approach inclusive of access to medical clinics, casework, social assistance as well as advocacy, research and outreach programmes. HealthServe was founded in 2006 on Christian values and since then has helped over 5,000 migrant workers.}

\section{Treating children in Argentinian slums} More children living in the slums of Buenos Aires will be provided with free dental care after international dental charity Dentaid

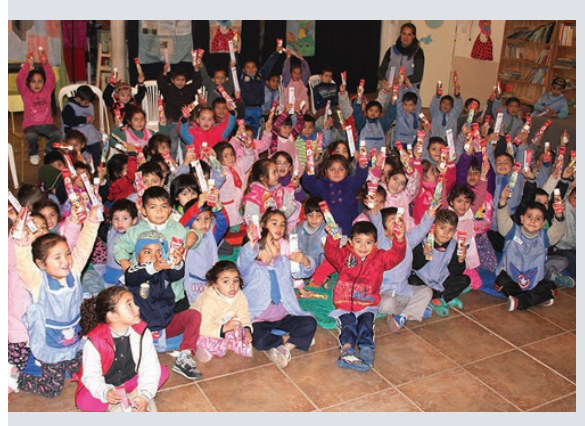

made a grant to Todos Juntos Children's Trust, a charity dedicated to improving oral health in the Argentinian capital.

Last year Todos Juntos provided 35,000 dental treatments for children living in desperately poor communities in Buenos Aires. The charity was established in 2005 after its founder, Fiona Watson, realised the extent of tooth decay among Argentinian children and the effect that a lack of access to dental services was having on their lives. Todos Juntos now operates three Sonrisa (meaning smile) clinics in Buenos Aries which provide free dental treatment for underprivileged children. The charity also runs oral health education sessions in surrounding schools (pictured), distributes toothbrushes and toothpaste and gives one-toone hygiene sessions for all its young patients. Services are provided by Argentinian dentists funded by Todos Juntos.

\section{Fundraising for East Africa}

Bridge2Aid is gearing up for its national fundraising day - Smile in Pink. This is a day during National Smile Month when people in the UK dental community come together to wear pink and fairy wings proudly for a very good cause - to ensure millions in East Africa have access to safe emergency dental treatment. This year, the event will take place on 2 June and Bridge2Aid is rounding up businesses, organisations, dental practices and supporters to join forces with thousands of others who believe that everyone has the right to be pain-free.

To register for Smile in Pink Day 2017 and receive your participant kit, email smileinpink@bridge2aid.org.

\section{Mission to Myanmar}

Henry Schein Dental UK supported Burmadent charity's recent mission to Myanmar (formerly Burma) by donating urgently needed healthcare products. During this mission, which has also been supported by dental materials provider VOCO, seven volunteers, four of whom were dentists, took care of more than 620 patients in nine days in remote rural areas of Myanmar. In addition, aftercare education was given.

Myanmar has poor dental services. There is no access to dentistry and oral neglect is rife. Many of the people are unable to afford or access dental treatment. Following a chance encounter while on holiday in Myanmar in 2012, Sharon Bierer and Henrik Overgaard-Nielsen organised a trip to Inle Lake in November 2012 to provide dental care to orphans at the Mein Thauk orphanage. Accompanied by two Burmese dentists and Lesley Naismith from Henry Schein Dental UK, they treated more than 1,200 patients around Lake Inle. As a result of this successful trip, Burmadent was founded and registered as a charity in the UK in 2013. 